Check for updates

Cite this: RSC Adv., 2018, 8, 36233

\title{
Production of cellulase by Trichoderma reesei from pretreated straw and furfural residues
}

\author{
Chun Hai Zhao, (DD *a Xiaoyan Liu, ${ }^{\text {b }}$ Tong Zhan ${ }^{\text {b }}$ and Jianlong He*c
}

In this study, furfural residues were used as a substrate for cellulase production by the fungi Trichoderma reesei. The results indicated that a low $\mathrm{pH}$ and the presence of lignin in the furfural residues have an obvious impact on cellulase production by $T$. reesei. After $\mathrm{pH}$ adjustment, furfural residues could be used for cellulase production by $T$. reesei, with a higher filter paper activity (FPA) and a higher activity of CMCase compared to that yielded from furfural residues with $\mathrm{pH}$ unadjusted. After being washed with $1.6 \%(\mathrm{w} / \mathrm{v}) \mathrm{H}_{2} \mathrm{O}_{2}$, all of the lignin in the furfural residues was removed, and an FPA of $7.1 \mathrm{FPU} \mathrm{ml}^{-1}$ and a CMCase activity of $3.4 \mathrm{IU} \mathrm{ml}^{-1}$ were obtained in $115 \mathrm{~h}$, while pretreated straw could yield an FPA of 8.0 FPU ml $\mathrm{ml}^{-1}$ and a CMCase activity of $2.7 \mathrm{IU} \mathrm{ml}^{-1}$ in $160 \mathrm{~h}$. Moreover, after being treated with $\mathrm{H}_{2} \mathrm{O}_{2}$, furfural residues could be used as an inducer in the production of cellulases. With the treated furfural residues added into the medium at the beginning of cultivation, T. reesei gave the maximum FPA (8.4 FPU $\mathrm{ml}^{-1}$ ) and CMCase activity $\left(4.8 \mathrm{IU} \mathrm{ml}^{-1}\right)$ at $142 \mathrm{~h}$ from pretreated straw, which is relatively high for cellulase production compared to that from most other agricultural wastes reported.

Received 12th July 2018

Accepted 7th October 2018

DOI: $10.1039 / \mathrm{c} 8 \mathrm{ra05936e}$

rsc.li/rsc-advances
The cost of cellulase is a significant factor in the economics of biomass to ethanol conversion technology. Thus, it has a direct impact on the cost of ethanol production, and therefore needs to be minimized. Reducing the cost of the growth medium and substrate is one of the critical factors for producing highly active cellulase inexpensively. ${ }^{\mathbf{1 0}}$ Lignocellulosic biomass is an abundant resource that can be used for the production of cellulase. The lignocellulosic material pretreated rice straw was selected as a carbon source for cellulase production in our previous study, while it was recently found that furfural residue is a more economic material for cellulase production. Furfural residue is an industrial waste product which is produced during the manufacture of furfural from corncob, but the environmentally friendly disposal and the utilization of furfural residues are significant challenges to the furfural industries. Furfural residue is a new carbon resource which contains $83.2 \%$ glucose, 5.6\% arabinose, and 5.9\% mannose, and it is said that the process of furfural production could decrease the degree of polymerization of cellulose, thus, the furfural residue is able to be easily hydrolyzed by cellulase. ${ }^{\mathbf{1 1}}$ Moreover, in the furfural production process, hemicelluloses are hydrolyzed to produce furfural under acid catalysis. Hemicelluloses in biomass have been cited as barriers to cellulase activity, ${ }^{12}$ but the furfural residues are almost free of hemicelluloses, ${ }^{13,14}$ and hence, furfural residues are a potential alternative source for cellulase production. In China, about 2.3 million tons of furfural residues are produced every year, but only small amounts are effectively used. As a raw material, the low cost of furfural residues means that they have the potential to reduce the cost of cellulase production. ${ }^{13}$ Studies on the 
utilization of furfural residues have shown its potential as a source of bioethanol, ${ }^{15}$ but there are few reports on the use of furfural residues as a substrate for cellulase production, though enzymatic hydrolysis of furfural residues is an energy saving and environmentally friendly method..$^{29-31}$ Thus, the aim of this study was to examine the potential utilization of furfural residues as substrates in cellulase production by $T$. reesei.

\section{Materials and methods}

\subsection{Strains and materials}

The cellulase producer used in this study was T. reesei. Furfural residue was collected from Shanxi, China and stored for later use in a freezer. The pretreated straw was kindly supplied by Baimai Green Biological Energy CO., LTD. (Huaian, China). The mineral medium for cellulase production contains $1.6 \mathrm{~g} \mathrm{l}^{-1}$ of corn steep liquor, $0.2 \mathrm{~g} \mathrm{l}^{-1}$ of $\mathrm{CoCl}_{2} \cdot 6 \mathrm{H}_{2} \mathrm{O}, 1.4 \mathrm{~g} \mathrm{l}^{-1}$ of $\left(\mathrm{NH}_{4}\right)_{2} \mathrm{SO}_{4}, 2.0 \mathrm{~g} \mathrm{l}^{-1}$ of $\mathrm{KH}_{2} \mathrm{PO}_{4}, 0.3 \mathrm{~g} \mathrm{l}^{-1}$ of $\mathrm{MgSO}_{4}$ and $0.3 \mathrm{~g} \mathrm{l}^{-1}$ of urea and was supplemented with various carbon sources as shown in Table 1.

\subsection{Cellulase production}

An inoculum of $1 \times 10^{7}$ spores was added to $3.0 \mathrm{ml}$ of culture medium in a test tube and grown at $30{ }^{\circ} \mathrm{C}$ under shaking $(200$ $\mathrm{rpm}$ ) for 24 hours. Then all of the preculture was inoculated into $100.0 \mathrm{ml}$ of induction medium in a $500 \mathrm{ml}$ flask. The culture for cellulase production was grown under shaking (200 rpm) at $30{ }^{\circ} \mathrm{C}$. The composition of the cellulase producing medium was the mineral medium supplemented with $30.0 \mathrm{~g} \mathrm{l}^{-1}$ of carbon sources. $10.0 \mathrm{~g} \mathrm{l}^{-1}$ Tween-80 was added to the culture medium at the beginning of the cultivation. The culture was centrifuged at $10000 \mathrm{~g}$ and $4{ }^{\circ} \mathrm{C}$ for $10 \mathrm{~min}$ and the cell-free culture supernatants were assayed to study the concentration of extracellular proteins and the enzyme production pattern over different phases of growth. All experiments were performed in triplicate.

\subsection{Analytical methods}

The total concentration of extracellular protein was assayed by the Lowry method, ${ }^{16}$ and bovine serum albumin was used as the standard protein. The filter paper activities (FPA) of the cellulase preparations were evaluated according to the method described by Ghose et al. ${ }^{17}$ After incubating at $50{ }^{\circ} \mathrm{C}$ for $1 \mathrm{~h}$, $3.0 \mathrm{ml}$ of dinitrosalicylic acid (DNS) was added to the mixture. The released glucose was measured with spectrophotometry, and the activity of the filter paper hydrolysis was evaluated based on the release of glucose, termed FPU that is defined here as the amount of enzyme which catalyzes the formation of 1 $\mu \mathrm{mol}$ of glucose per minute from the hydrolysis of filter paper under assay conditions. CMCase activity is measured by determining the amount of reducing sugars released after enzyme reaction with $20.0 \mathrm{~g} \mathrm{l}^{-1}$ of $\mathrm{CMC}$ at $\mathrm{pH} 4.8$ and $50{ }^{\circ} \mathrm{C}$ for $30 \mathrm{~min},{ }^{18}$ after which $3.0 \mathrm{ml}$ of DNS was added to the mixture. One unit (IU) of CMCase is defined as the amount of enzyme that liberates $1.0 \mu \mathrm{mol}$ of glucose per minute under assay conditions. The 3,5-dinitrosalicylic acid (DNS) assay was also used to assay the concentration of produced reducing sugars in the medium, using a glucose standard curve prepared at six different concentrations.

\section{Result and discussion}

\subsection{Effects of $\mathrm{pH}$ of furfural residues on cellulase production}

It has been reported that the $\mathrm{pH}$ of the medium has an obvious influence on cellulase production. ${ }^{20-22}$ The $\mathrm{pH}$ of the furfural residues is about 3-4 and a low $\mathrm{pH}$ might be an obstacle to cellulase production by $T$. reesei from furfural residues. Therefore in this study, the $\mathrm{pH}$ of the furfural residues was adjusted to 5-6 (F1) and this was then used for cellulase production by $T$. reesei. The strains of $T$. reese $i$ were grown on media F1, PS and F2 respectively, with samples taken at regular intervals, and then the cellulase activity and extracellular proteins of each culture was determined. The results in Fig. 1 show that the maximum FPA and CMCase activity produced by $T$. reesei on medium PS reached 8.1 FPU ml $\mathrm{Fu}^{-1}$ and $2.3 \mathrm{IU} \mathrm{ml}^{-1}$ after $160 \mathrm{~h}$ and $139 \mathrm{~h}$ of cultivation respectively, and the maximum FPA and CMCase activity produced by $T$. reesei on medium F1 reached $5.4 \mathrm{FPU} \mathrm{ml}^{-1}$ and $1.9 \mathrm{IU} \mathrm{ml}^{-1}$ after $115 \mathrm{~h}$ and $139 \mathrm{~h}$ of cultivation respectively, while T. reesei gave much lower FPA and CMCase activity on medium F2 (Fig. 1a and b). Similar time courses were observed for the extracellular protein production of $T$. reesei on media PS and F1, while the amount of protein produced by $T$. reesei on medium F2 is much lower than that on media PS and F1 (Fig. 1c). These results indicated that the low $\mathrm{pH}$ of the furfural residue had a negative effect on the secretion of extracellular protein as well as on the cellulase production, and that a $\mathrm{pH}$ of $5-6$ is suitable for cellulase production by $T$. reesei from furfural residues. It has been reported that

Table 1 The culture medium and carbon resources used in this study

\begin{tabular}{ll}
\hline Medium & Carbon resource \\
\hline PS & Pretreated straw \\
F1 & Furfural residues (pH adjusted to 5-6) \\
F2 & Furfural residues (pH 4-5, unadjusted) \\
F3 & Furfural residues (treated with $1.0 \%(\mathrm{w} / \mathrm{v}) \mathrm{H}_{2} \mathrm{O}_{2}$ and water, $\mathrm{pH} \mathrm{5-6)}$ \\
F4 & Furfural residues (treated with $1.6 \%(\mathrm{w} / \mathrm{v}) \mathrm{H}_{2} \mathrm{O}_{2}$ and water, $\mathrm{pH} \mathrm{5-6)}$ \\
PF1 & Pretreated straw with furfural residue added at 0 $\mathrm{h}(\mathrm{pH} 5-6)$ \\
PF2 & Pretreated straw with furfural residue added at $72 \mathrm{~h}(\mathrm{pH} 5-6)$ \\
PF3 & Pretreated straw with furfural residue added at 120 $\mathrm{h}(\mathrm{pH} 5-6)$
\end{tabular}




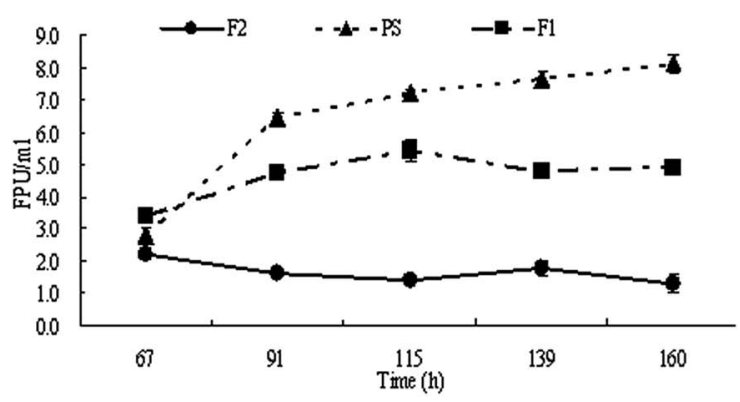

a

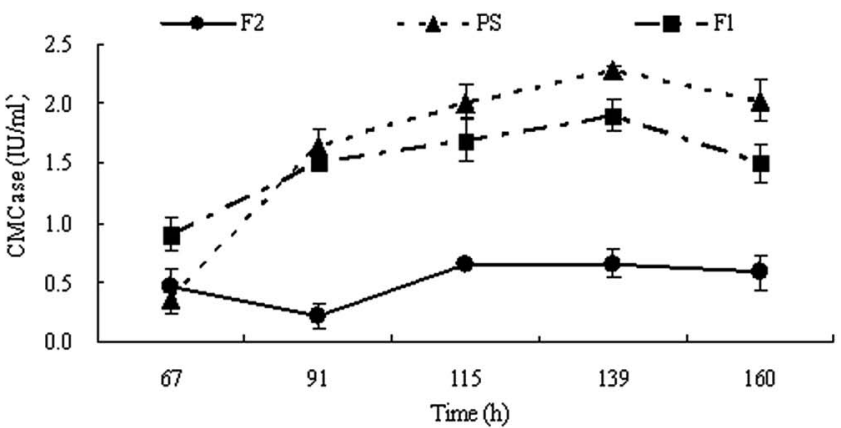

b

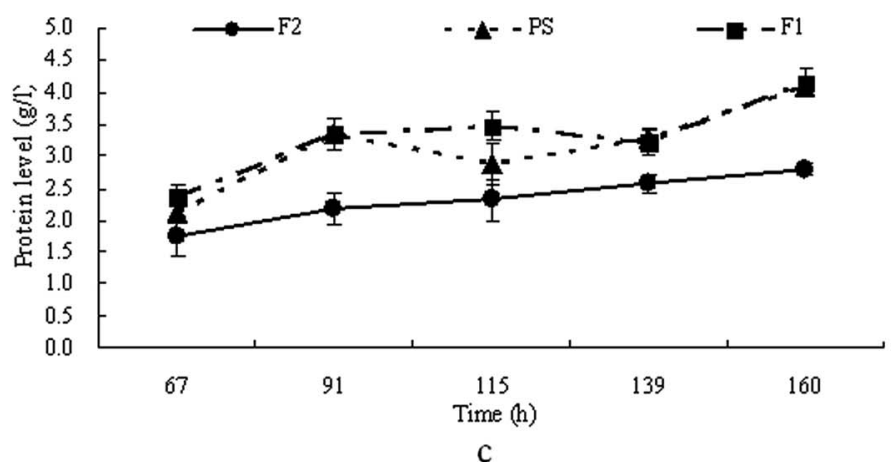

Fig. 1 Time course of FPA (a), CMCase (b) and extracellular protein production (c) on PS, F1 and F2 by T. reesei.

Aspergillus niger and $T$. viride gave a maximum cellulase production at $\mathrm{pH} 4.5$ and $\mathrm{pH} 5.5$ respectively, ${ }^{23}$ and also that $\mathrm{pH}$ 5-6 is favored by most fungi, ${ }^{17,23}$ which is consistent with our results.

\subsection{Effects of hemicellulose in furfural residues on cellulase production}

Hemicellulose hinders microbial attack, but it was reported that washing with $\mathrm{H}_{2} \mathrm{O}_{2}$ could remove most of the hemicellulose thus enhancing microbial utilization. ${ }^{13}$ Therefore in this study furfural residues were treated with $1.0 \%(\mathrm{w} / \mathrm{v}) \mathrm{H}_{2} \mathrm{O}_{2}$ and then washed to neutral with water (used as carbon resource in medium F3) or treated with $1.6 \%(\mathrm{w} / \mathrm{v}) \mathrm{H}_{2} \mathrm{O}_{2}$ and then washed to neutral with water (used as carbon resource in medium F4). T. reesei strains were then grown in culture media PS, F3 and F4 respectively. The cellulase activity and extracellular proteins in the medium were determined at regular intervals, and the time courses of the production of extracellular proteins and cellulase activities are shown in Fig. 2. Clearly, as shown in Fig. 2a, the FPA produced by $T$. reesei on media PS, F3 and F4 were not statistically different during the first $115 \mathrm{~h}$ of the culture. The maximum activities (6.4 FPU ml $\mathrm{ml}^{-1}$ and 7.1 $\mathrm{FPU} \mathrm{ml} \mathrm{m}^{-1}$ ) of FPA were observed at $115 \mathrm{~h}$ in $\mathrm{F} 3$ and $\mathrm{F} 4$ respectively, while the maximum activity of FPA on medium PS (8.0 FPU ml ${ }^{-1}$ ) was not observed until $160 \mathrm{~h}$ of cultivation. T. reesei showed the highest activities of CMCase on F4 (3.4 $\left.\mathrm{U} \mathrm{ml}^{-1}\right)$ followed by that of on F3 (3.2 $\mathrm{U} \mathrm{ml}^{-1}$ ) at $139 \mathrm{~h}$, while the CMCase in medium PS was much lower and reached its highest activity $\left(2.7 \mathrm{U} \mathrm{ml}^{-1}\right)$ at $160 \mathrm{~h}$ (Fig. 2b). In media F3 and F4, the protein level increased during the first 139 hours of cultivation, reached the maximum level at
$139 \mathrm{~h}$ and then decreased at the end of cultivation. However, in medium PS, the protein level kept increasing until the end of the cultivation (Fig. 1c), corresponding to the production of cellulase in medium PS.

In fact, the use of furfural residue for enzyme production has two advantages: the low cost and the ease of its hydrolysis. The furfural residue is made up of a matrix of cellulose and lignin with a small amount of hemicellulose. It was shown in Fig. 2a and $\mathrm{b}$ that when $T$. reese $i$ was grown on media $\mathrm{F} 3$ and $\mathrm{F} 4$, the strains both gave a lower FPA but a higher CMCase activity within a shortened cultivation time than that of the T. reesei grown on PS. One possible explanation is that the polymerization in the furfural residue is lower than that of in the pretreated straw for the removal of hemicellulose by $\mathrm{H}_{2} \mathrm{O}_{2}$. Hemicellulose causes hindrance in microbial attack, thus removing the hemicellulose in the furfural residue with $\mathrm{H}_{2} \mathrm{O}_{2}$ is required to enhance microbial utilization. The composition of the furfural residue after being washed with $1.0 \% \mathrm{H}_{2} \mathrm{O}_{2}$ was $64.1 \%$ cellulose and $32.4 \%$ lignin, while after being washed with $1.6 \% \mathrm{H}_{2} \mathrm{O}_{2}$, the composition of the furfural residue was $85.3 \%$ cellulose and $11.9 \%$ lignin. $^{13}$ The increase in cellulose was predominantly attributed to the decrease in lignin and makes the furfural residue more accessible to cellulase. ${ }^{13}$ It has been reported that the culture time of the highest cellulase activity depends upon the substrate, ${ }^{24}$ and the data in Fig. 2a and b showed that $T$. reesei produced lower FPA but higher CMCase on media F3 and F4 than on PS, and gave the highest cellulase activities in a shorter culture time, which indicated that the furfural residues were an ideal material for cellulase production by $T$. reesei. 


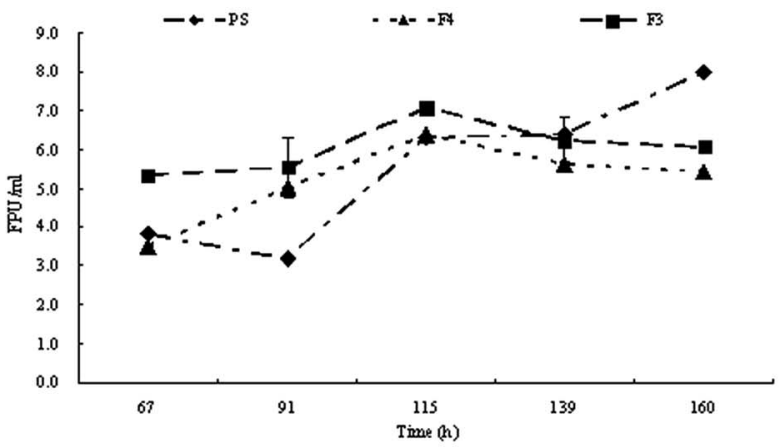

a

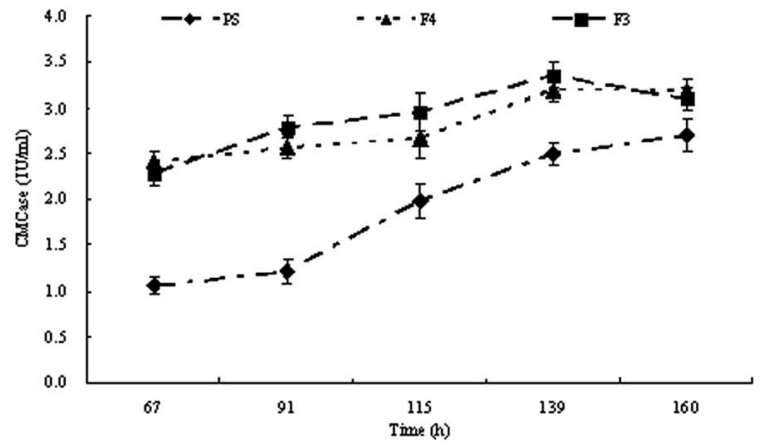

b

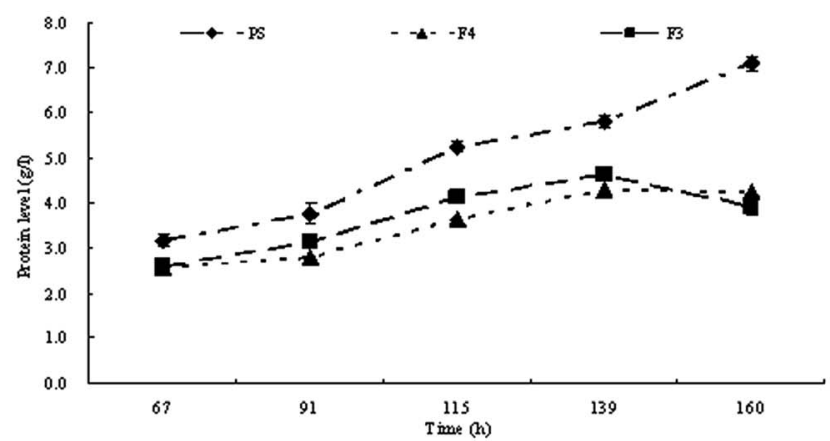

c

Fig. 2 Time course of FPA (a), CMCase (b) and extracellular protein production (c) on PS, F3 and F4 by T. reesei.

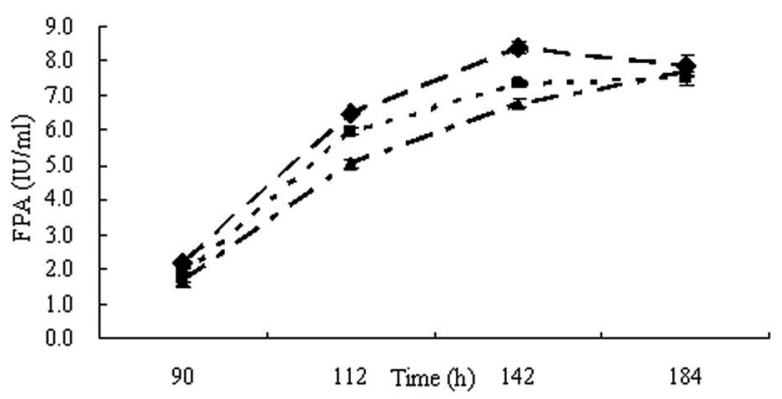

a

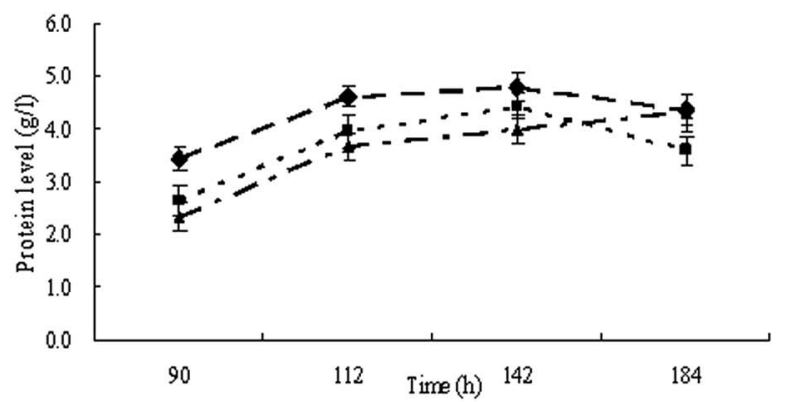

b

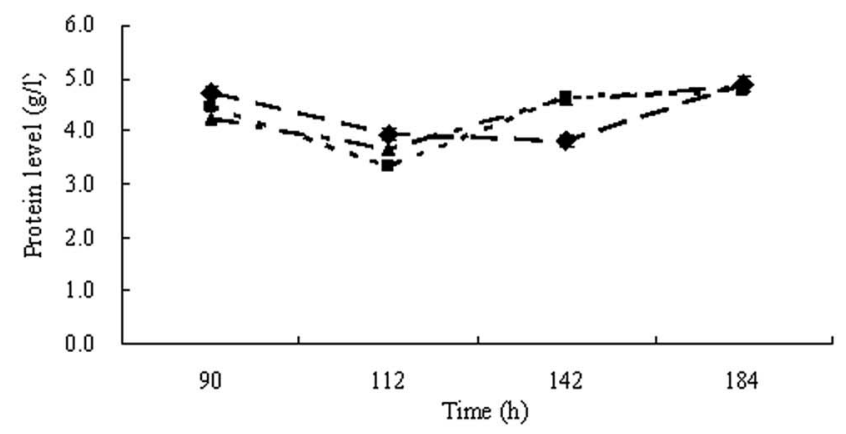

C

Fig. 3 Time course of FPA (a), CMCase (b) and extracellular protein production (c) by T. reesei when cultivated on medium PF1 ( $\bullet$ ), PF2 ( $\square$ ) and PF3 $(\boldsymbol{\Delta})$ respectively. 


\subsection{Cellulase production from pretreated straw supplemented with furfural residue}

The results above showed that with pretreated straw, T. reesei could have a higher activity of FPA, while with furfural residues T. reesei gave a higher activity of CMCase and produced FPA and CMCase activity within a shortened culture time. Therefore $T$. reesei strains were grown on mineral media containing $30.0 \mathrm{~g}$ $\mathrm{l}^{-1}$ of pretreated straw with $10.0 \mathrm{~g}^{-1}$ of furfural residue added, which were treated with $1.6 \% \mathrm{H}_{2} \mathrm{O}_{2}$ (furfural residue was added at the $0^{\text {th }}$ hour (PF1), $72^{\text {nd }}$ hour (PF2) and $120^{\text {th }}$ hour (PF3) of the cultivation respectively). The results in Fig. 3a show that when grown on media PF1 and PF2, T. reesei gave the maximum FPA of 8.4 FPU ml $\mathrm{Fi}^{-1}$ and 7.3 $\mathrm{FPU} \mathrm{ml} \mathrm{m}^{-1}$ respectively, which were both observed at $142 \mathrm{~h}$ of cultivation. When $T$. reesei strains were grown on medium PF3, the maximum FPA (7.7 FPU ml ${ }^{-1}$ ) was observed at the end of the cultivation $(184 \mathrm{~h})$. At the same time, a similar pattern was shown concerning the production of CMCase (Fig. 3b). It is shown in Fig. 3c that the patterns of extracellular protein production were similar in medium PF1, PF2, and PF3. These results indicated that supplementation of the furfural residue in pretreated straw at the beginning of the cultivation could clearly induce the production of cellulase as well as shorten the culture time.

The highest cellulase production value (based on filter paper activity) achieved in this study was $8.4 \mathrm{PFU} \mathrm{ml}^{-1}$ and was obtained when $T$. reesei strains were grown on medium PF1. The cellulase production by $T$. reesei with different substrates has been compared overall. It has been found that $0.7 \mathrm{FPU} \mathrm{ml}{ }^{-1}$ was produced from steam-treated willow by $T$. reese $i$ RUT C30 within $120 \mathrm{~h},{ }^{25}$ while when HAc was added as an inducer to the medium, an enhancement of cellulase production was observed, resulting in a cellulase activity of $1.6 \mathrm{FPU} \mathrm{ml} \mathrm{m}^{-1}{ }^{26} 2.1$ FPU $\mathrm{ml}^{-1}$ and 1.3 FPU ml $\mathrm{ml}^{-1}$ were respectively obtained from Solka Floc and lactose by T. reesei RUT C30 in 120 h. 1.7 FPU $\mathrm{ml}^{-1}$ of cellulase was produced from dairy manure in a culture time of $144 \mathrm{~h}^{19}$ With acid-swollen cellulose, T. reesei RUT C30 and $T$. reesei RUT NG14 could both produce $15.0 \mathrm{FPU} \mathrm{ml} \mathrm{m}^{-1}$ of cellulase ${ }^{27}$ For rice straw sticks, pretreatment with alkali led to the highest enzyme activity in the culture medium (1.1 FPU $\mathrm{ml}^{-1}$ ) within a $144 \mathrm{~h}$ culture. It is said that the pretreatment of the rice straw with alkali might cause the removal of lignin in the cellulose, such that the rest of the cellulose components could effectively induce the synthesis of enzymes by the fungal cells. ${ }^{28}$ For furfural residue, treatment with $\mathrm{H}_{2} \mathrm{O}_{2}$ could cause enormous changes of the components with all of the hemicellulose and most of the lignin being removed from the furfural residue. ${ }^{13}$ This removal of lignin could induce high cellulase activity produced by $T$. reesei in a shortened culture time. Therefore in this study, supplementation with furfural residue makes cellulase production by $T$. reesei from low cost pretreated straw more economic.

\section{Conclusion}

Low $\mathrm{pH}$ and the presence of lignin in furfural residues have a negative impact on cellulase production by $T$. reesei. After $\mathrm{pH}$ adjustment or the removal of lignin with $\mathrm{H}_{2} \mathrm{O}_{2}$, furfural residues can be used for cellulase production by $T$. reesei. When grown on a medium containing pretreated straw supplemented with furfural residues, a high activity of cellulase was produced by $T$. reese $i$ in a shortened culture time. $T$. reesei gave the maximum FPA (8.4 FPU ml ${ }^{-1}$ ) and CMCase activity $\left(4.8 \mathrm{IU} \mathrm{ml}^{-1}\right.$ ) at $142 \mathrm{~h}$ from pretreated straw, which is relatively high for cellulase production compared to from most other agricultural wastes reported.

\section{Conflicts of interest}

There are no conflicts to declare.

\section{Acknowledgements}

This work was supported by Jiangsu Key Laboratory for Biomass-based Energy and Enzyme Technology (Huaiyin Normal University) and was supported by the National Science Foundation of China (31200023) and National Natural Science Foundation (BS2012SW001) of Shan Dong Province and the J14LE58 and J17KA122, J18KZ008 Project of Shandong Province Higher Educational Science and Technology Program from Shandong Provincial Education Department.

\section{References}

1 C. P. Kubicek, M. Mikus, A. Schuster, M. Schmoll and B. Seiboth, Metabolic engineering strategies for the improvement of cellulase production by Hypocrea jecorina, Biotechnol. Biofuels, 2009, 2, 19.

2 C. P. Kubicek, The Cellulase Proteins of Trichoderma veesei: structure, multiplicity, mode of action and regulation of formation, Adv. Biochem. Eng./Biotechnol., 1992, 45, 1-22.

3 H. Q. Liu, Y. Feng, D. Q. Zhao and J. X. Jiang, Evaluation of cellulases produced from four fungi cultured on furfural residues and microcrystalline cellulose, Biodegradation, 2012, 23, 465-472.

4 D. Tisch, C. P. Kubicek and M. Schmoll, The phosducin-like protein PhLP1 impacts regulation of glycoside hydrolases and light response in Trichoderma reesei, BMC Genomics, 2011, 12, 613.

5 M. G. Adsul, M. S. Singhvi, S. A. Gaikaiwari and D. V. Gokhale, Development of biocatalysts for production of commodity chemicals from lignocellulosic biomass, Bioresour. Technol., 2011, 102, 4304-4312.

6 D. B. Wilson, Cellulases and biofuels, Curr. Opin. Biotechnol., 2009, 20, 295-299.

7 D. B. Wilson, Processive and nonprocessive cellulases for biofuel production-lessons from bacterial genomes and structural analysis, Appl. Microbiol. Biotechnol., 2012, 93, 497-502.

$8 \mathrm{~J}$. R. Cherry and A. L. Fidantsef, Directed evolution of industrial enzymes: an update, Curr. Opin. Biotechnol., 2003, 14(4), 438-443.

9 G. Stephanopoulos, Challenges in engineering microbes for biofuels production, Science, 2007, 315(5813), 801-804. 
10 G. P. Philippidis, Cellulase Production technology, in Enzymatic Conversion of Biomass for Fuel Production, ed. M. E. Himmel, et al., ACS symposium series, 1994, p. 566.

11 L. Zhang, T. Li, L. Wang and S. Z. Li, Enzymatic hydrolysis of corncob residues of furfural manufacture and optimum conditions for cellulose conversion, Trans. Chin. Soc. Agric. Eng., 2009, 25, 226-230.

12 B. Yang and C. E. Wyman, Effect of xylan and lignin removal by batch and flowthrough pretreatment on the enzymatic digestibility of corn stover cellulose, Biotechnol. Bioeng., 2004, 86(1), 88-98.

13 Y. Xing, L. X. Bu, K. Wang and J. X. Jiang, Pretreatment of furfural residues with alkaline peroxide to improve cellulose hydrolysis characterization of isolated lignin, Cellul. Chem. Technol., 2012, 46, 249-260.

14 S. N. Sun, X. F. Cao, F. Xu, G. L. Jones and M. Baird, Alkaline and organosolv lignins from furfural residue : structural features and antioxidant activity, BioResources, 2014, 9, $772-785$.

15 S. Zhang, Study on components of furfural residue from corncob, J. Northeast For. Univ., 1991, 2(1), 98-107.

16 O. H. Lowry, N. J. Rosebrough, A. L. Farr and R. J. Randall, Protein measurement with the folin phenol reagent, J. Biol. Chem., 1951, 193, 265-275.

17 T. K. Ghose, Measurement of cellulase activities, Pure Appl. Chem., 1987, 59, 257-268.

18 M. Mandels, R. Andreotti and C. Roche, Measurement of saccharifying cellulase, Biotechnol. Bioeng. Symp., 1976, 2133.

19 G. L. Miller, Use of dinitrosalicylic acid reagent for determination of reducing sugar, Anal. Chem., 1959, 31, 426-428.

20 Z. Wen, W. Liao and S. Chen, Production of cellulase by Trichoderma reesei from dairy manure, Bioresour. Technol., 2005, 96, 491-499.

21 Y. j. Lee, B. K. Kim, B. H. Lee, K. I. Jo, N. K. Lee, C. H. Chung, Y. C. Lee and J. W. Lee, Purification and characterization of cellulase produced by Bacillus amyoliquefaciens DL-3 utilizing rice hull, Bioresour. Technol., 2008, 99, 378-386.

22 M. Sohail, R. Siddiqi, A. Ahmad and S. A. Khan, Cellulase production from Aspergillus niger MS82: effect of temperature and pH, New Biotechnol., 2009, 25(6), 437-441.

23 A. Das, S. Bhattacharya, K. S. Roopa and S. S. Yashoda, Microbial utilization of agronomic wastes for cellulase production by Aspergillus niger and Trichoderma viride using solid-state fermentation, Dyn. Biochem. Process Biotechnol. Mol. Biol., 2011, 5(2), 18-22.

24 T. V. Ojumu, B. O. Salomon, E. Betiku, S. K. Layokun and B. Amigun, Cellulase Production by Aspergillus flavus Linn isolate NSPR 101 fermented in sawdust, bagasse and corncob, Afr. J. Biotechnol., 2003, 2(6), 150-152.

25 K. Reczey, Z. Szengyel, R. Eklund and G. Zacchi, Cellulase production by T. reesei, Bioresour. Technol., 1996, 57, 25-30.

26 Z. Szengyel and G. Zacchi, Effect of acetic acid and furfural on cellulase production of Trichoderma reesei RUT C30, Appl. Biochem. Biotechnol., 2000, 89, 31-42.

27 B. S. Montenecourt and D. E. Eveleigh, Selective screening methods for the isolation of high yielding cellulase mutants of Trichoderma reesei, Adv. Chem. Ser., 1979, 181, 289-301.

28 W. C. Sun, C. H. Cheng and W. C. Lee, Protein expression and enzymatic activity of cellulases produced by Trichoderma reesei Rut C-30 on rice straw, Process Biochem., 2008, 43, 1083-1087.

29 H. Q. Liu, Y. Feng, D. Q. Zhao and J. X. Jiang, Evaluation of cellulases produced from four fungi cultured on furfural residues and microcrystalline cellulose, Biodegradation, 2012, 23(3), 465-472.

30 H. Q. Liu, Y. Feng, J. X. Jiang and L. W. Zhu, Enzymatic Hydrolysis of Furfural Residues Using Crude Trichoderma cellulases, Adv. Mater. Res., 2011, 236-238, 452-455.

31 H. Yu, X. Li, W. Zhang, D. Sun and J. Jiang, Hydrophilic pretreatment of furfural residues to improve enzymatic hydrolysis, Cellulose, 2015, 22(3), 1675-1686. 